\title{
ANÁLISE TÉCNICA E ECONÔMICA DA ATIVIDADE LEITEIRA DO IFET-BAMBUÍ, EM MINAS GERAIS, NO PERÍODO DE 2012 A 2014
}

\author{
U. CORRÊA ${ }^{1}$, B. P. V. B. RIBEIRO ${ }^{1}$, M. A. LOPES $^{1}$, J. W. PRADO ${ }^{1}$, B. W. A. CORRÊA ${ }^{2}$ e F. M. CARVALHO ${ }^{1}$ \\ ${ }^{1}$ Universidade Federal de Lavras, ${ }^{2}$ Instituto Federal de Minas Gerais - Campus Bambuí \\ uellington.correa@gmail.com*
}

Submetido 10/01/2017 - Aceito 24/04/2018

DOI: $10.15628 /$ holos.2018.5537

\section{RESUMO}

A falta de informações sobre o real custo dos serviços públicos provoca uma demanda social em saber qual a qualidade dos gastos públicos. Entretanto, há uma carência de estudos práticos que abordam a gestão de custos aplicados a instituições do setor público. Assim, objetivou-se estimar e avaliar os custos da atividade leiteira do Instituto Federal de Minas Gerais - Campus Bambuí, no período de 2012 a 2014, com a finalidade de obter um diagnóstico gerencial. A abordagem da pesquisa caracteriza-se como quali-quantitativa; em relação aos objetivos, é classificada como descritiva e explicativa, e, quanto aos procedimentos, define-se como pesquisa documental e estudo de caso. O estudo demonstrou que a atividade é subsidiada e depende de recursos financeiros do governo para manter a atual estrutura produtiva, pois não possui viabilidade operacional mínima, ou seja, os recursos próprios não são suficientes para arcar com os gastos operacionais. Dessa forma, será necessário rever a atual estrutura produtiva do setor de bovinocultura e seu planejamento de gastos, uma vez que os recursos empregados na atividade são públicos e precisam ser aplicados de forma eficaz e eficiente para que gerem a maior quantidade de benefícios e atenda às expectativas da sociedade.

PALAVRAS-CHAVE: Bovinocultura leiteira, gestão de custos, setor público.

\section{TECHNICAL AND ECONOMIC ANALYSIS OF DAIRY ACTIVITY IN IFET-BAMBUÍ, IN MINAS GERAIS, FOR THE PERIOD 2012 TO 2014}

\begin{abstract}
The lack of information about the real cost of utilities causes a social demand to know what the quality of public spending. However, there is a lack of practical studies that address on cost management applied to public sector institutions. Thus, this study aimed to investigate and evaluate the cost of dairy production of the Federal Institute of Minas Gerais Campus Bambuí in the period 2012-2014, in order to get a managerial diagnosis. The research approach is characterized as qualitative and quantitative, in relation to the objectives is classified as descriptive and explanatory, and on the procedures defined as documentary research and case
\end{abstract}

study. The study showed that the activity is subsidized and depends on government financial resources to maintain the current production structure because the activity does not have minimum operational viability, i.e., own resources are not enough to pay for operating expenses. Thus, it is necessary to review the current production structure of the cattle industry and the structure of spending, since the resources used in the activity are public and need to be applied effectively and efficiently to generate the most benefits and meets the expectations of society.

KEYWORDS: Dairy cattle, cost management, public sector. 


\section{INTRODUÇÃO}

A falta de informações sobre o custo real dos serviços públicos provoca uma demanda social em saber qual a qualidade dos gastos públicos. E, na tentativa de ofertar transparência à gestão dos recursos, as instituições têm adotado práticas gerenciais da administração do setor privado com o intuito de obter maior capacidade gerencial, pois há uma tendência de aplicar, ao setor público, os princípios gerenciais de eficácia, eficiência e avaliação de resultados.

Na literatura corrente, alguns pesquisadores têm se engajado no debate sobre a adoção de processos gerenciais do setor privado pelas entidades públicas, como Bozeman e Bretschneider (1994), Newman e Clarke (1994), Carroll e Garkut (1996), Keen e Murphy (1996), Box (1999), Boyne (2002), Meier et al. (2007), Boyne e Walker (2010).

A gestão de custos é uma ferramenta gerencial típica do setor privado que tem sido adotada pelas entidades na gestão dos recursos públicos. Na literatura nacional, Alonso (1999), Reinert (2005), Magalhães et al. (2010), Machado e Holanda (2010), Ching, Silveira e Freire (2011), Corrêa et al. (2016), debatem, em seus estudos, sobre a importância da adoção da gestão de custos pelas entidades públicas.

Catelan et al. (2013) salientam que ter conhecimento sobre os custos de uma atividade é fundamental ao seu controle, pois é possível comparar resultados anteriores com os atuais e fornecer previsões sobre o comportamento dos custos das atividades da entidade. Corrêa et al. (2015), por sua vez, afirmam que a técnica de gestão de custos, amplamente difundida em organizações do setor privado, pode ser perfeitamente empregada na gestão pública como forma de mensurar o desempenho dos serviços prestados à sociedade.

Entretanto, há uma carência de estudos práticos que abordam a gestão de custos aplicados às instituições do setor público. Assim, este artigo procura aplicar esta técnica à gestão de uma Instituição Federal de Ensino Superior (IFES).

Diante disso, com esta pesquisa, objetivou-se estimar e avaliar os custos da atividade leiteira do Instituto Federal de Minas Gerais (IFMG) - Campus Bambuí, no período de 2012 a 2014, visando obter um diagnóstico gerencial desta atividade produtiva. Para a consecução do objetivo proposto, foram apurados e estudados os índices zootécnicos, as fontes de receitas e os custos operacionais efetivos e totais da atividade leiteira do Campus.

\section{REFERENCIAL TEÓRICO}

Este embasamento teórico faz uma breve abordagem sobre a importância da gestão de custos para o setor público e discorre sobre resultados de pesquisas anteriores acerca da gestão de custos aplicados à atividade leiteira desenvolvida em diferentes sistemas produtivos. 


\subsection{A importância da gestão de custos para o setor público}

Fornecer serviços que atendam às expectativas da população e que sejam eficientes é uma das funções das organizações do setor público (Boyne; Walker, 2010). Contudo, os recursos públicos necessitam ser gerenciados de forma eficiente para que a administração pública consiga atingir melhores resultados e suprir a demanda dos cidadãos.

Neste contexto, Catelan et al. (2013) afirmam que a contabilidade de custos é uma ferramenta gerencial imprescindível ao setor público e que pode auxiliar os gestores na alocação eficiente dos recursos produtivos. Ainda conforme Catelan et al. (2013, p. 5), "apurar o custo do serviço público é necessário para se estimar a qualidade do mesmo, já que a eficiência é a relação entre os resultados e o custo para obtê-los".

Slomski (2009), por sua vez, argumenta que, no Brasil, a contabilidade de custos aplicada à administração pública ainda se encontra em fase embrionária, e os gestores públicos devem conhecer os custos das atividades no intuito de tomar melhores decisões gerenciais, como em decidir produzir ou comprar.

$\mathrm{Na}$ visão de Callado et al. (2005) e Bertó e Beulke (2006), a gestão eficiente da contabilidade de custos objetiva avaliar a gestão dos estoques de materiais, apurar os custos dos produtos ou serviços vendidos, avaliar as imobilizações próprias, avaliar os bens de fabricação própria para o uso futuro, subsidiar o critério para a formação de preços, analisar a rentabilidade proporcionada pelas diversas atividades, dentre outros fins, além de servir como instrumento para o planejamento operacional e financeiro da entidade. E, segundo Megliorini (2007), a gestão dos custos subsidia a apuração dos gastos com insumos aplicados na produção, no controle das operações e atividades, nas políticas de redução de desperdícios e no planejamento orçamentário da instituição.

Horngren, Datar e Foster (2004) complementam argumentando que a eficiência operacional das organizações passa necessariamente pela gestão estratégica dos custos, e a contabilidade de custos fornece informações para a contabilidade gerencial e financeira. Além disso, a gestão de custos fornece aos gestores suporte para a tomada de decisões no que diz respeito aos aspectos produtivos (Lopes et al., 2004).

No Brasil, a gestão de custos públicos ganhou maior repercussão entre os pesquisadores e gestores públicos após a homologação da Lei Complementar no 101, de 04 de maio de 2000, Lei de Responsabilidade Fiscal (LRF), e da Lei Complementar no 131, de 27 de maio de 2009, Lei da Transparência, que acrescentou dispositivos à LRF (Catelan et al., 2013). A LRF, de acordo com Xavier Júnior, Queiroz e Miranda (2013), estabeleceu que a administração pública mantivesse um sistema de custos que permitisse avaliar e acompanhar a gestão orçamentária, financeira e patrimonial.

Porém, antes da homologação da LRF e com o intuito de obter maior controle dos gastos públicos, o governo, a partir de 1986, criou a Secretaria do Tesouro Nacional (STN), do Ministério da Fazenda. Neste mesmo período, foi implantado, junto à administração pública, o Sistema Integrado de Administração Financeira (SIAFI), que visa proporcionar maior rigor e controle da execução das despesas orçadas pelo governo (Alonso, 1999). 


\subsection{Estudos sobre custos e rentabilidade na atividade leiteira}

Lopes e Carvalho (2000) e Lopes, Santos e Carvalho (2012) afirmam que a análise operacional da atividade leiteira pode viabilizar o negócio à medida que o gestor conhece e gerencia os fatores de produção (terra, trabalho e capital) de forma eficiente. A literatura nacional fornece estudos relacionados à análise de custos e análise operacional da atividade leiteira em diferentes sistemas de produção. Citam-se as pesquisas de Lopes et al. (2004), Carvalho, Ramos e Lopes (2009), Moura et al. (2010), Lopes et al. (2011), Lopes, Santos e Carvalho (2012) e Silva e Silva (2013).

Lopes et al. (2004) estudaram a rentabilidade da atividade leiteira de 16 sistemas de produção de leite na região de Lavras, Minas Gerais, e identificaram que os itens componentes do custo operacional efetivo (COE) que exerceram maior influência sobre os custos da atividade leiteira foram a alimentação, mão de obra, despesas diversas, energia, sanidade, ordenha, impostos e inseminação artificial. A análise econômica apresentou margem líquida positiva e resultado negativo, sendo que a atividade leiteira tinha condições de produzir em médio prazo, e, em longo prazo, os pecuaristas estão descapitalizando.

Carvalho, Ramos e Lopes (2009), após compararem os custos de produção do leite e a influência deles na lucratividade de duas propriedades localizadas no município de Unaí, Minas Gerais, nos anos de 2003 e 2004, concluíram que o aumento de escala de produção diluiu os custos fixos da atividade, diminuindo o custo total e aumentando as margens e, ainda, que o uso de tecnologias viáveis possibilitou melhor resposta do sistema a diversos fatores de produção.

Moura et al. (2010), ao avaliarem os custos de produção, as receitas e a rentabilidade da atividade leiteira de seis sistemas de produção de leite bovino no Cariri Paraibano, constataram que a receita bruta da atividade foi suficiente para cobrir os custos operacionais efetivos e totais de quatro das seis propriedades estudadas. Ademais, os itens que compõem o custo operacional efetivo de produção do leite foram responsáveis por percentuais superiores a $60 \%$ em todas as propriedades analisadas.

Lopes et al. (2011) estudaram a rentabilidade de um sistema de produção leiteira de um centro de pesquisa, situado na região de Varginha, Minas Gerais. Na análise, a margem bruta, a margem líquida e o resultado foram negativos, evidenciando que o sistema de produção de leite estava se descapitalizando e se endividando. E, ainda, que os itens componentes do custo operacional efetivo que exerceram maior influência sobre a receita do leite e sobre o custo operacional efetivo foram: alimentação, mão de obra, impostos e taxas, sanidade, ordenha, despesas diversas, reprodução e energia.

Também Minas Gerais, Lopes, Santos e Carvalho (2012) estimaram e compararam indicadores econômicos de fazendas leiteiras com alto volume de produção diária, em regimes de semiconfinamento e de confinamento total. Foram utilizados os dados de seis sistemas de produção de leite, sendo três em semiconfinamento e três em confinamento total. Os sistemas de produção em semiconfinamento apresentaram viabilidade econômica e condições de produzir no curto, médio e longo prazo, com consequente capitalização dos pecuaristas. Já os sistemas de 
produção em confinamento total apresentaram margem bruta negativa, indicando que os produtores estavam se descapitalizando e se endividando.

Em Goiás, Silva e Silva (2013), foram analisados os indicadores zootécnicos e econômicos de um sistema de produção de leite a pasto com suplementação. A propriedade estudada possuía um sistema de produção lucrativo; contudo, poderia melhorar os indicadores zootécnicos buscando o equilíbrio econômico/zootécnico, visto que a fazenda possuía potencial para a produção de leite por ter apresentado custos inferiores à média das propriedades da região.

\section{MATERIAL E MÉTODOS}

Este estudo foi desenvolvido no setor de bovinocultura de leite do Instituto Federal de Educação, Ciência e Tecnologia de Minas Gerais - Campus Bambuí, a partir da coleta e da compilação de dados de sua atividade leiteira.

O setor de bovinocultura leiteira da instituição pesquisada possui apenas fins educacionais Corrêa et al. (2017), onde são desenvolvidas aulas práticas ofertadas aos alunos dos cursos de ciências agrárias. Entretanto, esta atividade produtiva possui recursos próprios gerados por meio da comercialização da produção de leite in natura e venda de animais. Assim, pressupõe-se que a atividade apresenta viabilidade operacional mínima, uma vez que possui receita própria para reinvestimento e manutenção de sua atividade produtiva.

A abordagem desta pesquisa caracteriza-se como quali-quantitativa; em relação aos objetivos, é classificada como descritiva e explicativa; e, quanto aos procedimentos, define-se como pesquisa documental e estudo de caso.

Na pesquisa quali-quantitativa, as informações de natureza qualitativa são apresentadas em conjunto com as de natureza quantitativa. Lunde, Heggen e Strand (2012) afirmam que, ao se adotar métodos mistos de pesquisa, adquire-se o conhecimento que não estaria disponível apenas em estudos quantitativos e qualitativos realizados separadamente.

A pesquisa descritiva fundamenta-se na análise documental para descrever os fatos e fenômenos de determinada realidade a partir da observação, do registro, da análise e da correlação dos fatos e variáveis (Triviños, 1987; Cervo; Bervian, 2002). A pesquisa explicativa, por sua vez, identifica os fatores que contribuem para a ocorrência de determinado fenômeno (Gil, 2007).

Em relação à pesquisa documental, esta utiliza diversificadas fontes de dados para selecionar, tratar e interpretar a informação sem tratamento analítico, de modo a obter um sentido para os dados que serão analisados (Silva; Grigolo, 2001). Já o estudo de caso envolve um único ou múltiplos casos, sendo um tipo de pesquisa que permite uma análise profunda do problema pesquisado com base em uma ampla variedade de evidências do objeto de estudo (Eisenhardt; Graebner, 2007).

A análise contempla o período compreendido entre os anos de 2012 e 2014, e a tabulação dos dados foi realizada utilizando-se planilhas eletrônicas do software Microsoft Office Excel ${ }^{\circledR}$, desenvolvidas especificamente para este fim. 
Apurou-se o valor atual de cada ativo e a data de sua aquisição, sendo o tempo de vida útil de cada bem determinado com base no disposto da Instrução Normativa da Receita Federal do Brasil no. 162, de 31 de dezembro de 1998, que dispõe sobre o prazo de vida útil de bens imóveis, móveis e semoventes.

Para o cálculo da depreciação, foi utilizado o método linear, onde a desvalorização do bem ocorre de forma constante durante sua vida útil, ou seja, as cotas financeiras são fixas (Lopes; Carvalho, 2000). Para este cálculo, empregou-se a Equação 1:

$$
\text { Depreciação }=\underline{V i-V f}
$$

$n$

Onde: $V_{i}$ é o valor atual do bem; $V_{f}$ é o valor final do bem; e $n$ é a vida útil do bem pelo método linear.

A instituição realiza a reposição do rebanho por meio de recria. Desse modo, não foi considerada a depreciação dos animais, com exceção de três animais de tração que foram depreciados. Lopes et al. (2004 e 2011) afirmam que, no sistema onde é avaliado o custo da atividade como um todo, envolvendo os custos de cria, recria de fêmeas de reposição e a manutenção de vacas secas, não se considera a depreciação das matrizes, no intuito de evitar a duplicidade de lançamentos de despesas.

Os insumos consumidos na atividade leiteira do Campus são provenientes de compras por meio de licitação, como ocorre no setor público. Nesta pesquisa, admitiu-se que os insumos, ao serem retirados do almoxarifado da instituição, eram consumidos no ato de sua retirada. Assim, foram coletados dados de gastos com alimentação (milho, farelo de soja, caroço de algodão, farelo de trigo, ureia pecuária, suplemento vitamínico para vacas em lactação e para bezerras e bezerros, minerais para vacas em lactação e demais animais, ração peletizada para bezerras e bezerros e equinos, manutenção de pastagens e silagem), inseminação artificial, sanidade animal, limpeza e manutenção da ordenha, demais custos de manutenção do setor e despesas com consumo de material de escritório.

A silagem, que compõe o item de gastos com alimentação, é proveniente do cultivo de milho (Zea mays) realizado nas dependências da instituição, que, por sua vez, mensura os custos de produção com a lavoura de milho e ensilagem.

Foi mensurado o custo da ração que constitui a dieta das vacas em lactação, bezerras e bezerros. Este concentrado é produzido no próprio Campus, em seu setor de fábrica de ração. Integram os custos do concentrado os gastos com milho, farelo de soja, ureia, farelo de trigo, caroço de algodão, suplemento vitamínico para vacas em lactação e para bezerras e bezerros, custos com mão de obra terceirizada, energia elétrica e depreciação dos bens do setor.

Em relação ao desmame dos bezerros, este ocorre de forma precoce. O bezerro é desmamado após as primeiras 24 horas, que é o período para ingestão de colostro (imunoglobulinas). Em seguida, são direcionados para um piquete com casas de proteção (bezerreiro), onde, até os 70 dias de vida, são alimentados com sucedâneo lácteo e, após esse período, com feno e ração, para estímulo do rúmen e produção de bactérias proteolíticas. 
Como não existe medidor de consumo de energia elétrica específico para cada setor do Campus, foi solicitado ao funcionário especializado da instituição o consumo médio de energia elétrica de todos os motores e demais equipamentos do setor de fábrica de ração e do setor de bovinocultura, para que fosse estimado o consumo médio de energia elétrica o mais próximo possível do real.

A área total destinada à atividade leiteira da instituição é de 120 ha, sendo que, destes, 20 ha são destinados à cultura de milho para silagem. O sistema de criação é conduzido em regime semi-intensivo, em pastagens de Urocloa decumbens, U. brizantha (MG5), Megathyrsus maximus (capim-mombaça) e Cynodon spp. (capim-tifton 85).

O setor de bovinocultura possui área construída de $769,96 \mathrm{~m}^{2}$, com sala de aula, escritório, cozinha, sala de ordenha e estábulos, curral com calçamento de $500 \mathrm{~m}^{2}$ de piso de concreto, silo do tipo trincheira, com capacidade de $240 \mathrm{~m}^{2}$, tanque térmico de resfriamento de leite com capacidade para 3.000 litros e balança para pesagem de bovinos.

O rebanho é formado por animais da raça Girolando, com diferentes grupos genéticos. Constatou-se que o manejo reprodutivo é feito por inseminação artificial, sendo todo o rebanho composto por vacas em lactação, vacas secas, crias e recrias (Tabela 1).

Tabela 1: Composição do rebanho do IFET Bambuí. (2012-2014).

\begin{tabular}{lcccc}
\hline \multicolumn{1}{c}{ Categoria animal } & \multicolumn{3}{c}{ Período } & Média \\
\cline { 2 - 5 } & 2012 & 2013 & 2014 & 34 \\
\hline Vacas em lactação & 35 & 36 & 33 & 34 \\
Vacas secas & 41 & 63 & 51 & 52 \\
Fêmeas de 1a 12 meses & 33 & 17 & 29 & 26 \\
Machos de 1 a 12 meses & 14 & 21 & 18 & 17 \\
Fêmeas de 13 a 24 meses & 22 & 15 & 15 & 17 \\
Machos de 13 a 24 meses & 2 & 4 & 8 & 4 \\
Fêmeas 25 a 36 meses & 34 & 25 & 21 & 27 \\
Touros & 0 & 0 & 0 & 0 \\
Total do rebanho & 179 & 180 & 173 & 177 \\
\hline
\end{tabular}

Fonte: Elaborado pelos autores a partir dos dados da pesquisa (2016).

As vacas em lactação recebem suplementação alimentar com concentrado, silagem de milho e suplementação mineral. As vacas secas e parte das crias, apenas silagem de milho e minerais, enquanto a outra parte das crias recebe suplementação com concentrado, silagem de milho e minerais.

As ordenhas são realizadas pela manhã, às $7 \mathrm{~h}$, e à tarde, às $15 \mathrm{~h} 30$, em ordenhadeira mecânica, tipo espinha de peixe. Para a higienização desta, utilizam-se detergentes, como ácido alcalino e sanitizante clorado, em momentos específicos, antes e após a ordenha. Para o tanque de expansão (armazenagem do leite), há um detergente específico de limpeza.

Em relação à higienização das vacas durante a ordenha, são utilizados os seguintes procedimentos: a vaca entra na ordenha e passa pelo teste da mastite clínica, onde os três primeiros jatos de cada teto são tirados em uma caneca de fundo escuro com ranhuras. Caso seja verificada a presença de grumos, esta vaca passa para o lote de tratamento de mastite. Caso 
contrário, faz-se o pré-dipping (imersão dos tetos em solução de iodo glicerinado com água), espera-se 30 segundos e é realizada a limpeza com papel-toalha. Finalizados esses procedimentos, a ordenha é realizada e, em seguida, faz-se o pós-dipping (imersão dos tetos em uma solução pura de iodo glicerinado).

As vacas em lactação são divididas em 5 lotes de ordenha e seguem rigorosamente a seguinte sequência, para evitar a transmissão da mastite: lote 1 - primíparas - que nunca tiveram mastite (novilhas de primeira cria); lote 2 - vacas de segunda cria em diante que nunca deram mastite (alta produção); lote 3 - vacas de segunda cria em diante, que já deram mastite, mas estão curadas (alta produção); lote 4 - vacas de baixa produção; e lote 5 - vacas com mastite que estão em tratamento.

As receitas do setor de bovinocultura foram provenientes do excedente da produção de leite in natura (que era vendido para uma indústria de laticínios próxima à região do município de Bambuí), do repasse de leite in natura para o laticínio do Campus (onde são processados e produzidos os derivados do leite, sendo uma parte consumida no próprio Campus e outra comercializada), e do repasse de animais vivos para o setor de abatedouro da instituição.

O maior descarte de vacas é devido a problemas com mastite clínica crônica, em que os animais apresentam sintomas inflamatórios e claras alterações na secreção do leite (aspecto e quantidade), sendo comum a perda definitiva da função do quarto mamário devido à fibrose tecidual. Os animais devem ser eliminados, pois são portadores e fontes de contaminação das demais vacas.

O adubo orgânico gerado na atividade não foi contabilizado como receita, pois não foi possível mensurar o volume produzido devido à falta de dados. Ele era utilizado como fertilizante nas pastagens do próprio setor de bovinocultura.

Para estimar o valor da receita do $\mathrm{kg} / \mathrm{leite}$ repassado para o laticínio do Campus, foi considerado o valor pago aos produtores da região do kg/leite in natura; enquanto, para estimar a receita de animais abatidos, considerou-se o preço de mercado de animais na região, em kg/vivo, com rendimento de $50 \%$ de carcaça.

A metodologia utilizada para apurar e estruturar os custos da atividade leiteira foi a do custo operacional proposto por Matsunaga et al. (1976) - método que estima o Custo Operacional Total (COT) e o Custo Operacional Efetivo (COE). O COE refere-se aos custos de todos os recursos de produção que exigem desembolso, enquanto o COT é a soma do COE com outros custos não desembolsáveis, como a depreciação (Lopes; Carvalho, 2000).

Compõem o COE da atividade leiteira os gastos com alimentação, inseminação artificial, sanidade, ordenha, mão de obra de funcionários públicos e terceirizados, energia elétrica, custos com manutenção do setor e despesas diversas (Lopes e Lopes, 1999).

A mão de obra do setor é formada por dois funcionários públicos, um técnico em agropecuária e um veterinário, e três funcionários terceirizados. $O$ técnico em agropecuária possui dedicação exclusiva ao setor, enquanto o veterinário trabalha em regime parcial, pois presta serviços a outros setores de produção animal do Campus. Para a estimativa do custo dos serviços 
do veterinário, foi atribuído o valor de $25 \%$ em relação ao valor total de sua mão de obra, já que este setor demanda maior tempo de dedicação.

Por ser uma instituição pública, com fins educacionais, em que a atividade leiteira é voltada ao ensino, nesta pesquisa não foram consideradas as remunerações do capital investido, da terra e do capital de giro.

Os indicadores de eficiência econômica avaliados na atividade foram calculados a partir da receita total (venda de leite + consumo interno de leite + animais abatidos), sendo mensurada a margem bruta (receita bruta - COE), margem líquida (receita bruta - COT), rentabilidade (COE/margem bruta), margem bruta por $\mathrm{kg} /$ leite (margem bruta/kg de leite produzido) e margem líquida por kg/leite (margem líquida/kg de leite produzido) (Lopes et al., 2004).

Para obter o ponto de equilíbrio, ou seja, a quantidade de produção de leite mínima que deveria ser produzida, onde a atividade leiteira possui seus custos totais iguais às suas receitas totais (Lopes; Carvalho, 2000), os custos foram classificados em variáveis (alimentação, mão de obra, sanidade, inseminação artificial, ordenha e energia elétrica) e fixos (depreciação, custos com manutenção do setor e despesas diversas) e, posteriormente, aplicados à Equação 2:

$$
Q=\frac{C F}{P-C V_{U}}
$$

Onde: $Q$ é a quantidade de leite, em kg; $C F$ é o custo fixo total; $C V u$ é o custo variável unitário; e $P$ é o preço de mercado do produto.

\section{RESULTADOS E DISCUSSÃO}

Os índices técnicos de desempenho produtivo do setor de bovinocultura do Campus estão apresentados na Tabela 2. Nota-se que o percentual de vacas em lactação está distante do índice de $83,0 \%$, o ideal para intervalos de partos de 12 meses, e do índice de 55,0\%, para vacas com menor eficiência reprodutiva que apresentam intervalos de partos de 18 meses (Embrapa, $2001 \mathrm{e}$ 2010).

A produtividade leiteira da atividade foi de $149.495 \mathrm{~kg} / \mathrm{ano}$, e a produção diária por vaca em lactação foi $12,0 \mathrm{~kg}$ - semelhantes às observadas por Magalhães et al. (2011) em vacas girolandas mantidas em pastagens de capim-elefante e concentrados. Já Lopes et al. (2011) encontraram índices de produtividade por vacas em lactação de 13,76 kg/dia com animais da raça Girolando de diferentes grupos genéticos.

A área das vacas em lactação compreende 8,5 ha, sendo dividida em 4 piquetes com capim Mombaça (espécie Panicum maximum), apresenta alta produtividade de matéria seca, qualidade e adaptação a diferentes condições de clima e solo. Neste cenário, no ano de 2012, eram 4,12 animais/ha; em 2013, 4,24 animais/ha; e, em 2014, 3,88 animais/ha.

Considerando que a média de peso vivo das vacas lactantes é de $400 \mathrm{~kg}$ e que $1 \mathrm{UA}$ (Unidade Animal) equivale a $450 \mathrm{~kg}$ de peso vivo (Embrapa, 2003), no ano de 2012 a taxa de 
lotação era de 3,66 UA/ha; em 2013, de 3,76 UA/ha, e, em 2014, de 3,45 UA/ha, sendo considerado um sistema intensivo de produção.

No manejo com as pastagens, é realizada a adubação nitrogenada e fosfatada, além de fertirrigação rotativa nos piquetes com dejetos suínos advindos de biodigestor de fluxo tubular presente no setor de suínos da instituição.

Em média, a taxa de ocupação de vacas em lactação/área foi de 4,08 animais/ha. Quanto ao índice de vacas em lactação/homem, a média foi de 8,7 animais/homem. Lopes et al. (2011) encontraram índices de vacas em lactação/área de 1,21 animais/ha, e de vacas em lactação/homem, de 11,3 animais/homem. Lopes, Santos e Carvalho (2012), em estudo sobre propriedade com alto volume de produção leiteira diária, encontraram índice de vacas em lactação/área de 1,27 animais/ha, e índice de vacas em lactação/homem, em média, de 31,78 animais/homem.

Tabela 2: Índices técnicos de desempenho produtivo IFET Bambuí. (2012-2014).

\begin{tabular}{lcccccc}
\hline \multirow{2}{*}{ Desempenho médio anual } & \multicolumn{3}{c}{ Período } & \multirow{2}{*}{ Média } & DP \\
\cline { 2 - 4 } & 2012 & 2013 & 2014 & & 12 \\
Quantidade total de vacas & 76 & 99 & 84 & 86 & 12 \\
Quantidade de vacas em lactação & 35 & 36 & 33 & 34 & 2 \\
Percentual de vacas em lactação & $45,7 \%$ & $36,0 \%$ & $38,9 \%$ & $40,2 \%$ & $5,0 \%$ \\
Produção total de leite/kg/ano & 147.129 & 152.986 & 148.371 & 149.495 & 3.086 \\
Produção diária de leite/kg & 403 & 419 & 406 & 410 & 8 \\
Produtividade diária leite/kg/vaca & 11,7 & 11,8 & 12,5 & 12,0 & 0,4 \\
Área destinada à bovinocultura (ha) & 120 & 120 & 120 & 120 & 0 \\
Área destinada ao cultivo de milho (ha) & 20 & 20 & 20 & 20 & 0 \\
Área destinada a vacas em lactação (ha) & 8,5 & 8,5 & 8,5 & 8,5 & 0 \\
Quantidade de vacas em lactação/ha & 4,12 & 4,24 & 3,88 & 4,08 & 0,18 \\
Área destinada ao bezerreiro (ha) & 4,5 & 4,5 & 4,5 & 4,5 & 0 \\
Intervalo entre partos & 16 & 16 & 16 & 16 & 0 \\
Produtividade leite/kg/ha & $1.226,1$ & $1.274,9$ & $1.236,4$ & $1.245,8$ & 25,7 \\
Mão de obra permanente (homem/dia) & 4 & 4 & 4 & 4 & 0 \\
Relação total de vacas/homem & 19,0 & 24,8 & 21,0 & 21,6 & 2,9 \\
Relação vacas em lactação/homem & 8,8 & 9,0 & 8,3 & 8,7 & 0,4 \\
Relação total do rebanho/homem & 44,8 & 45,0 & 43,3 & 44,4 & 0,9 \\
\hline
\end{tabular}

Fonte: Elaborado pelos autores a partir dos dados da pesquisa (2016).

${ }^{1}$ Não inclui a mão de obra do veterinário, pois este não tem dedicação exclusiva ao setor; DP: desvio padrão.

A partir dos resultados encontrados nesta pesquisa e em comparação com os encontrados por Lopes et al. (2011) e Lopes, Santos e Carvalho (2012), infere-se que a atividade de bovinocultura leiteira do Campus Bambuí possui ociosidade no índice de vacas em lactação/homem, ou seja, existe mão de obra ociosa no setor.

A Tabela 3 apresenta a análise de rentabilidade da atividade leiteira. Verifica-se que os custos produtivos foram superiores às receitas auferidas nos três períodos estudados. Assim, conclui-se que a atividade não possui viabilidade em termos econômicos para o Campus Bambuí.

Os indicadores de rentabilidade (margem bruta, margem líquida e rentabilidade) apresentaram resultados negativos nos três anos estudados. Apesar de serem negativos, os 
indicadores de rentabilidade no último ano (2014) de análise foram mais próximos de zero em relação aos dois primeiros anos (2012 e 2013), ou seja, a atividade obteve um déficit menor em comparação aos dois primeiros anos de estudo. Isto foi causado pelo aumento da receita gerada por animais abatidos na instituição, conforme as escriturações zootécnicas do setor.

Para Lopes, Cardoso e Demeu (2009), a rentabilidade na atividade leiteira está diretamente ligada aos índices de produtividade obtidos (Tabela 2), pois estes possuem influência direta no resultado da atividade. Desta forma, foi possível identificar os gargalos produtivos por meio do índice que apresenta maior influência negativa no desempenho da atividade. Corrigir os índices é fator determinante para minimizar os custos, maximizar a produção e, por conseguinte, obter melhor desempenho produtivo e maior rentabilidade.

Tabela 3: Análise de rentabilidade da atividade leiteira da instituição pública de ensino analisada.

\begin{tabular}{lccc}
\hline \multicolumn{1}{c}{ Descrição } & \multicolumn{3}{c}{ Período } \\
\cline { 2 - 4 } & 2012 & 2013 & 2014 \\
\hline Receita & $137.479,62$ & $184.516,53$ & $259.121,28$ \\
Leite indústria & $43.304,08$ & $48.181,67$ & $50.656,48$ \\
Leite laticínio IFMG & $73.017,04$ & $102.590,93$ & $93.307,15$ \\
Animais abatidos & $21.158,50$ & $33.743,93$ & $115.157,65$ \\
$\quad$ Custo Operacional Total (COT) & $407.365,02$ & $437.442,71$ & $417.442,44$ \\
$\quad$ Depreciação & $15.292,12$ & $17.336,68$ & $17.613,60$ \\
$\quad$ Custo Operacional Efetivo (COE) & $392.072,90$ & $420.106,03$ & $399.828,84$ \\
$\quad$ Alimentação & $199.507,23$ & $203.721,19$ & $179.704,40$ \\
$\quad$ Reprodução & $1.917,31$ & $4.077,64$ & $7.433,40$ \\
$\quad$ Sanidade & $9.353,67$ & $9.353,67$ & $2.955,98$ \\
$\quad$ Ordenha & $5.210,01$ & $5.210,01$ & $9.076,18$ \\
$\quad$ Mão de obra de funcionários públicos & $66.588,09$ & $85.974,02$ & $88.344,98$ \\
$\quad$ Mão de obra de terceirizados & $103.749,96$ & $107.208,26$ & $107.899,92$ \\
$\quad$ Energia elétrica & $4.409,76$ & $3.458,52$ & $2.872,32$ \\
$\quad$ Custos manutenção & 593,69 & 359,54 & 881,78 \\
$\quad$ Despesas diversas & 743,18 & 743,18 & 659,88 \\
Margem Bruta & $-254.593,28$ & $-235.589,49$ & $-140.707,56$ \\
Margem Líquida & $-269.885,40$ & $-252.926,17$ & $-158.321,16$ \\
Rentabilidade & $-64,94 \%$ & $-56,08 \%$ & $-35,19 \%$ \\
Margem bruta / kg de leite & $-1,73$ & $-1,54$ & $-0,95$ \\
Margem líquida / kg de leite & $-1,83$ & $-1,65$ & $-1,07$ \\
Ponto de equilíbrio & $*$ & $*$ & $*$ \\
\hline
\end{tabular}

Fonte: Elaborado pelos autores a partir dos dados da pesquisa (2016).

* Não foi possível estimar, pois o custo variável unitário foi maior que o preço unitário da venda do leite.

$\mathrm{Na}$ Tabela 4, está apresentado o resultado da representatividade de cada item de receita em relação à receita bruta total. Em média, a receita de leite in natura, consumido no próprio Campus (48,24\%), foi a mais representativa durante o período de análise, seguida pela receita de abate de animais $(26,04 \%)$ e da receita de leite in natura vendido para uma indústria da região $(25,72 \%)$. 
Tabela 4: Representatividade de cada item na receita, em percentual (\%), da instituição pública de ensino analisada.

\begin{tabular}{lccccc}
\hline \multicolumn{1}{c}{ Descrição } & \multicolumn{3}{c}{ Período } & Média & DP \\
\cline { 2 - 5 } & 2012 & 2013 & 2014 & & \\
\hline Leite indústria & 31,50 & 26,11 & 19,55 & 25,72 & 58 \\
Leite laticínio IFMG & 53,11 & 55,60 & 36,01 & 48,24 & 10,67 \\
Animais abatidos & 15,39 & 18,29 & 44,44 & 26,04 & 16,00 \\
\hline \multicolumn{1}{c}{ Total da receita } & 100,00 & 100,00 & 100,00 & & \\
\hline
\end{tabular}

Fonte: Elaborado pelos autores a partir dos dados da pesquisa (2016).

DP: desvio padrão.

Observa-se, ainda, que a receita de animais abatidos no ano de 2014 foi maior em relação às receitas advindas da produção de leite in natura. Lopes, Almeida Júnior e Carvalho (2003) e Moura et al. (2010) afirmam que a venda do excedente de animais contribui de forma significativa para elevar o desempenho da atividade leiteira, como ocorreu de forma mais representativa no último ano $(44,44 \%)$ de análise deste estudo.

Por meio dos resultados apresentados na Tabela 5, verifica-se que, em média, o item alimentação $(48,11 \%)$ foi o mais representativo entre os itens que compõem o COE, seguido pela mão de obra terceirizada (26,32\%) e mão de obra pública $(19,85 \%)$.

Tabela 5: Representatividade de cada grupo de despesa no custo operacional efetivo em percentual (\%) da instituição pública de ensino analisada.

\begin{tabular}{lccccc}
\hline & \multicolumn{3}{c}{ Descrição } & \multicolumn{3}{c}{ Período } & Média & DP \\
\cline { 2 - 4 } & 2012 & 2013 & 2014 & & 2,99 \\
Alimentação & 50,89 & 48,49 & 44,95 & 48,11 & 0,70 \\
Inseminação artificial & 0,49 & 0,97 & 1,86 & 1,11 & 0,91 \\
Sanidade & 2,39 & 2,23 & 0,74 & 1,78 & 0,57 \\
Ordenha & 1,33 & 1,24 & 2,27 & 1,61 & 2,61 \\
Mão de obra pública & 16,98 & 20,46 & 22,10 & 19,85 & 0,74 \\
Mão de obra terceirizada & 26,46 & 25,52 & 26,99 & 26,32 & 0,21 \\
Energia elétrica & 1,12 & 0,82 & 0,72 & 0,89 & 0,15 \\
Custos com manutenção & 0,15 & 0,09 & 0,22 & 0,07 \\
Despesas diversas & 0,19 & 0,18 & 0,17 & 0,18 & 0,01 \\
\hline \multicolumn{1}{c}{ Total das despesas } & 100,00 & 100,00 & 100,00 & & \\
\hline
\end{tabular}

Fonte: Elaborado pelos autores a partir dos dados da pesquisa (2016).

DP: desvio padrão.

Lopes et al. (2009) avaliaram propriedades produtoras de leite em função de seu nível tecnológico e encontraram diferentes resultados de representatividade do item de alimentação no total do COE, sendo de 57,36\%, 57,10\% e 46,21\% para sistema de baixo, médio e alto nível de tecnologia, respectivamente. Já Lopes et al. (2011) e Lopes e Santos (2012) encontraram resultados de $61,39 \%$ e 60,95\%, respectivamente, para o item de alimentação no total do COE.

Quando se analisa os resultados de representatividade das despesas em relação ao total do $\mathrm{COE}$, constata-se que o percentual médio do item alimentação $(48,11 \%)$, neste estudo, está entre os percentuais das propriedades de médio $(57,10)$ e alto $(46,21 \%)$ nível tecnológico encontrados por Lopes et al. (2009) e abaixo dos encontrados por Lopes et al. (2011) e Lopes e Santos (2012). 
Para o item mão de obra, Lopes et al. (2009) encontraram resultados médios da representatividade no total do COE de 17,16\%, 19,48\% e 20,02\% em sistemas de baixo, médio e alto nível tecnológico, respectivamente. Já Lopes et al. (2011) e Lopes e Santos (2012) observaram resultados de $18,10 \%$ e $11,76 \%$, respectivamente, na representatividade no total do COE.

Os percentuais médios do item mão de obra terceirizada e pública, juntos, somam $46,17 \%$ do COE. Este resultado, somado ao resultado do índice de vacas em lactação/homem (8,7 vacas para cada homem), que demonstrou ser ocioso, leva a inferir que a mão de obra do sistema produtivo estudado está em excesso, causando elevados custos produtivos.

A Tabela 6 mostra a representatividade de cada grupo de custo com alimentação no COE. Os resultados demonstram que, em média, o custo com silagem de milho $(21,51 \%)$ foi o mais representativo, seguido pelo item ração para vacas em lactação $(18,75 \%)$.

Tabela 6: Representatividade de cada grupo de custo com alimentação no COE em percentual (\%) da instituição pública de ensino analisada.

\begin{tabular}{|c|c|c|c|c|c|}
\hline \multirow{2}{*}{ Descrição } & \multicolumn{3}{|c|}{ Período } & \multirow{2}{*}{ Média } & \multirow{2}{*}{ DP } \\
\hline & 2012 & 2013 & 2014 & & \\
\hline Ração para vacas em lactação & 19,09 & 19,59 & 17,58 & 18,75 & 1,05 \\
\hline Ração para bezerras e bezerros & 2,53 & 3,36 & 5,78 & 3,89 & 1,69 \\
\hline Minerais para vacas em lactação & 0,52 & 1,79 & 1,29 & 1,20 & 0,64 \\
\hline Minerais para bovinos & 0,94 & 0,55 & 0,26 & 0,58 & 0,34 \\
\hline Ração peletizada para bezerras e bezerros & 1,83 & 0,86 & 0,90 & 1,19 & 0,55 \\
\hline Ração peletizada para equinos & 0,00 & 0,04 & 0,01 & 0,02 & 0,02 \\
\hline $\begin{array}{l}\text { Manutenção de pastagens (adubos e } \\
\text { fertilizantes, sementes para pastagens e material } \\
\text { para cercas) }\end{array}$ & 2,00 & 0,00 & 0,89 & 0,96 & 1,00 \\
\hline Silagem & 23,98 & 22,31 & 18,24 & 21,51 & 2,95 \\
\hline Total da alimentação & 50,89 & 48,49 & 44,95 & & \\
\hline
\end{tabular}

Fonte: Elaborado pelos autores a partir dos dados da pesquisa (2016).

DP: desvio padrão.

O custo médio com silagem de milho (21,51\%) está acima do valor de $12,73 \%$ encontrado na pesquisa de Carvalho, Ramos e Lopes (2009), enquanto o custo médio com ração para vacas em lactação (18,75\%) ficou abaixo dos resultados encontrados por Moura (2010) e Lopes et al. (2011), que foram, em média, de 47,05\% e 43,49\%, respectivamente.

O resultado encontrado para o item ração para vacas em lactação, neste estudo, pode estar superestimado, pois o consumo deste item, de acordo com os dados encontrados na pesquisa, foi de 1,84 kg de concentrado para $3 \mathrm{~kg}$ de leite produzido, desviando-se do padrão de consumo geral, que, de acordo com Carvalho, Ramos e Lopes (2009), é de 1 kg de concentrado para $3 \mathrm{~kg}$ de leite produzido.

$\mathrm{Na}$ Tabela 7, são demonstrados os valores de preço médio de venda e custos médios de produção do $\mathrm{kg} / \mathrm{leite} / \mathrm{ano}$ durante o período de análise. O preço médio do $\mathrm{kg} /$ leite in natura ( $\mathrm{R} \$$ $0,91)$, recebido na comercialização da produção, ficou abaixo do custo operacional efetivo do $\mathrm{kg} /$ leite $(\mathrm{R} \$ 2,73)$ e do custo operacional total do $\mathrm{kg} / \mathrm{leite}(\mathrm{R} \$ 2,85)$, revelando que a atividade leiteira do Campus Bambuí está deficitária e carece de gerenciamento para obter melhor resultado operacional. 
Tabela 7: Preço médio de venda e custos médios de produção kg/leite/ano da instituição pública de ensino analisada.

\begin{tabular}{lrrrrr}
\hline \multicolumn{1}{c}{ Descrição } & \multicolumn{3}{c}{ Período } & \multirow{2}{*}{ Média } & \multirow{2}{*}{ DP } \\
\cline { 2 - 5 } & 2012 & 2013 & 2014 & & \\
\hline Preço médio de venda do leite & 0,78 & 0,99 & 0,97 & 0,91 & 0,11 \\
Custo operacional efetivo & 2,74 & 2,76 & 2,71 & 2,73 & 0,03 \\
Custo operacional total & 2,84 & 2,87 & 2,83 & 2,85 & 0,02 \\
\hline
\end{tabular}

Fonte: Elaborado pelos autores a partir dos dados da pesquisa (2016).

Legenda: DP é o desvio padrão.

\section{CONSIDERAÇÕES FINAIS}

A atividade leiteira desenvolvida no Campus Bambuí possui apenas fins educacionais; porém, gera receita própria que contribui para sua manutenção. Este estudo demonstrou que a atividade é subsidiada e depende de recursos financeiros da instituição para manter a atual estrutura produtiva, pois não possui viabilidade operacional mínima, ou seja, os recursos próprios não são suficientes para arcar com os gastos operacionais.

Embora a atividade leiteira esteja operando à base de subsídios, ela é fundamental na formação educacional dos alunos, pois oferece meios para o desenvolvimento de pesquisas, além de oferecer o conhecimento das práticas agropecuárias. Este setor permite ao aluno desenvolver suas habilidades técnicas por meio da vivência com as situações reais da atividade produtiva.

A partir dos resultados dos índices zootécnicos, observa-se que existe deficiência no gerenciamento da atividade, pois foi encontrada baixa taxa de lotação das pastagens, baixo percentual de vacas em lactação em relação ao total do rebanho, baixa produtividade de $\mathrm{kg} /$ leite/vaca/dia e alta ociosidade da mão de obra permanente, quando se faz uma análise em comparação com outros estudos na mesma linha de pesquisa.

Por meio da análise de rentabilidade, ficou evidenciado que a atividade não possui viabilidade operacional, pois está se descapitalizando, no curto e longo prazo, constatada pelo resultado negativo da margem bruta, líquida e rentabilidade.

Quanto à composição do custo operacional efetivo, ele foi influenciado pelos gastos da atividade na seguinte ordem decrescente: alimentação, mão de obra terceirizada, mão de obra pública, sanidade, ordenha, inseminação, energia elétrica, despesas diversas e custos com manutenção. $E$, dentre os itens que compõem a alimentação do rebanho, a representatividade sobre o custo operacional efetivo foi na seguinte ordem decrescente: silagem, ração para vacas em lactação, ração para bezerras e bezerros, minerais para vacas em lactação, ração peletizada para bezerros (as), manutenção de pastagens, suplementação mineral para bovinos e ração peletizada para equinos.

Com base nos resultados, constata-se que será necessário rever a atual estrutura produtiva e os gastos do setor de bovinocultura do IFMG - Campus Bambuí, pois os recursos financeiros empregados na atividade, que são públicos, precisam ser aplicados de forma mais eficaz e eficiente para que gerem o maior número de benefícios e atenda às expectativas da sociedade. 


\section{REFERÊNCIAS}

Alonso, M. (1999). Custos no serviço público. Revista do Serviço Público, 50(1).

Associação Brasileira dos Criadores de Girolando. (2014). Índices Zootécnicos. Recuperado em 19 de abril, 2014 de www.girolando.com.br

Bertó, D. J.; Beulke, R. (2006). Gestão de custos. São Paulo: Saraiva.

Box, R. (1999). Running government like a business: implications for public administration theory and research. American Review of Public Administration, 29(1), 19-43.

Boyne, G. A. (2002). Public and private management: what's the difference? Journal of Management Studies, 39(1).

Boyne, G. A.; Walker, R. M. (2010). Strategic Management and Public Service Performance: The Way Ahead. Public Administration Review, Special Issue, 185-192.

Bozeman, B.; Bretschneider, S. (1994). The publicness puzzle in organization theory: A test of alternative explanations of differences between public and private organizations. Journal of Public Administration Theory and Research, 4(2), 197-223.

Callado, A. L. C.; Almeida, M. A.; Callado, A. A. C. (2005). Gestão de custos em micros, pequenas e médias empresas: um perfil dos artigos publicados no Congresso Brasileiro de Custos. In: IX Congresso Internacional de Custos, Florianópolis, Anais de congresso. Florianópolis: IX Congresso Internacional de Custos.

Carroll, B.; Garkut, D. (1996). Is there empirical evidence of a trend towards managerialism? A longitudinal study of six countries. Canadian Public Administration, 39(4), 535-553.

Carvalho, F. M.; Ramos, E. O.; Lopes, M. A. (2009). Análise comparativa dos custos de produção de duas propriedades leiteiras, no município de Unaí-MG, no período de 2003 e 2004. Ciência e Agrotecnologia, 33(Edição Especial), 1705-1711.

Catelan, D. W.; Martins, R. S.; Gouvea, D. M. R.; Negreiros, L. F.; Carvalho, S. C.; Vieira, S. F. A. (2013). Custos, desempenho e estrutura educacional do ensino fundamental: uma análise no município de Rolândia/PR. In: XX Congresso Brasileiro de Custos, Uberlândia, Anais de congresso. Uberlândia: XX Congresso Brasileiro de Custos.

Cervo, A. L.; Bervian, P. A. (2002). Metodologia científica. 5. ed., São Paulo: Prentice Hall.

Ching, H. Y.; Silveira, H. F. R.; Freire, F. S. (2011). Gestão de custos em administração pública: um estudo de caso do governo da Bahia e do Banco Central do Brasil. Revista de Economia e Administração, 10(2), 262-284.

Corrêa, U.; Benedicto, G. C.; Carvalho, F. M.; Campos, R. S.; Lopes, M. A.; Ribeiro, B. P. V. B. (2016). Study of costs and revenue from the production and practice laboratories of the Federal 
Institute of Science and Technology of Minas Gerais - Campus Bambuí. Ciência $e$ Agrotecnologia (Online), Lavras, 40, 337-346.

Corrêa, U.; Dominik, E. C.; Reis, R. P.; Ribeiro, B. P. V. B. (2015). Gestão de custos na autarquia pública: um estudo de caso na coordenadoria regional de Bambuí do Instituto Mineiro de Agropecuária. Contexto, Porto Alegre, 15(29), 62-77.

Corrêa, U.; Lopes, M. A.; Ribeiro, B. P. V. B.; Benedicto, G. C.; Silva, I. M.; Correa, B. W. A. (2017). Análise operacional da atividade leiteira do Instituto Federal de Ciência e Tecnologia de Minas Gerais Campus Bambuí. Custos e Agronegocio On Line, 13, 262-283.

Eisenhardt, K. M. Graebner, M. E. (2007). Theory building from cases: opportunities and challenges. Academy of management journal, 50(1), 25-32.

Empresa Brasileira de Pesquisa Agropecuária-EMBRAPA. (2001). Composição do rebanho e sua importância no manejo. Instrução técnica para o produtor de leite, 32, Juiz de Fora, MG.

Empresa Brasileira de Pesquisa Agropecuária-EMBRAPA. (2003). Área do piquete e taxa de lotação no pastejo rotacionado. Comunicado técnico, 101, Planaltina, DF.

Empresa Brasileira de Pesquisa Agropecuária-EMBRAPA. (2010). Eficiência reprodutiva das vacas leiteiras. Circular técnica, 64, São Carlos, SP.

GIL, A. C. (2007). Como elaborar projetos de pesquisa. 4. ed. São Paulo: Atlas.

Horngren, C. T.; Datar, S. M.; Foster, G. (2004). Contabilidade de custos. 11. ed., São Paulo: Prentice Hall.

Instrução Normativa no. 162, de 31 de dezembro de 1998. Fixa prazo de vida útil e taxa de depreciação dos bens que relaciona. Receita Federal do Brasil. Recuperado em 03 de outubro, 2014 de http://www.receita.fazenda.gov.br

Keen, L.; Murphy, P. (1996). Devolved budgetary management in local government: lessons from a shire county. Financial Accountability and Management, 12(1), 37-52.

Lei Complementar no. 101, de 04 de maio de 2000. Estabelece normas de finanças públicas voltadas para a responsabilidade na gestão fiscal e dá outras providências. Brasil. Recuperado em 19 de abril, 2014 de www.planalto.gov.br

Lei Complementar no. 131, de 27 de maio de 2009. Acrescenta dispositivos à Lei Complementar no 101, de 4 de maio de 2000, que estabelece normas de finanças públicas voltadas para a responsabilidade na gestão fiscal e dá outras providências. Brasil. Recuperado em 19 de abril, 2014 de www.planalto.gov.br

Lopes, M. A.; Almeida Júnior, G. A.; Carvalho, F. M. (2003). Rentabilidade de um sistema de produção de leite tipo B: um estudo de caso com a raça Jersey, no Estado de São Paulo. Revista Economia Rural, 2(2), 215-221. 
Lopes, M. A.; Cardoso, M. G.; Demeu, F. A. (2009). Influência de diferentes índices zootécnicos na composição e evolução de rebanhos bovinos leiteiros. Ciência Animal Brasileira, 10(2), 446453.

Lopes, M. A.; Carvalho, F. de M. (2000). Custo de produção do leite. Boletim agropecuário, 33, Lavras: UFLA.

Lopes, M. A.; Gomide, D. R.; Franco Neto, A.; Santos, G. (2011). Resultados econômicos de um sistema de produção de leite na região de Varginha - sul de Minas Gerais. Boletim da Indústria Animal, 68(1), 07-15.

Lopes, M. A.; Lima, A. L. R.; Carvalho, F. M.; Reis, R. P.; Santos, I. C.; Saraiva, F. H. (2004). Controle gerencial e estudo da rentabilidade de sistemas de produção de leite na região de Lavras (MG). Ciência e Agrotecnologia, 28(4), 883-892.

Lopes, M. A.; Lopes, D. C. F. (1999). Desenvolvimento de um sistema computacional para cálculo do custo de produção do leite. Revista Brasileira de Agroinformática, 2(1), 1-12.

Lopes, M. A.; Santos, G. (2012). Comparativo econômico entre propriedades leiteiras em sistema intensivo de produção: um estudo de multicasos. Revista Brasileira de Saúde e Produção Animal, 13(3), 591-603.

Lopes, M. A.; Santos, G.; Carvalho, F. M. (2012). Comparativo de indicadores econômicos da atividade leiteira de sistemas intensivos de produção de leite no Estado de Minas Gerais. Revista Ceres, 59(4), 458-465.

Lunde, A.; Heggen, K.; Strand, R. (2012). Knowledge and Power: exploring unproductive interplay between quantitative and qualitative researchers. Journal of Mixed Methods Research, 7(2), 197-210.

Machado, N.; Holanda, V. B. (2010). Diretrizes e modelo conceitual de custos para o setor público a partir da experiência no governo federal do Brasil. RAP - Revista de Administração Pública, 44(4), 791-820.

Magalhães, E. A.; Silveira, S. F. R.; Abrantes, L. A.; Ferreira, M. A. M.; Wakin, V. R. (2010). Custo do ensino de graduação em instituições federais de ensino superior: o caso da Universidade Federal de Viçosa. RAP - Revista de Administração Pública, 44(3), 637-66.

Magalhães, J. A.; Rodrigues, B. H. N.; Araújo Netto, R. B.; Costa, N. L.; Bezerra, E. E.; Santos, J. M.; Pompeu, R. C. F. F. (2011). Produção de leite com vacas mestiças em capim-elefante. Pubvet (Londrina), 5, 1226.

Matsunaga, M.; Bemelmans, P. F.; Toledo, P. E. N.; Dulley, R. D.; Okawa, H.; Pedroso, I. A. (1976). Metodologia de custo de produção utilizada pelo IEA. Agricultura em São Paulo, 23(1), 123139. 
Megliorini, E. (2007). Custos: análise e gestão. 2. ed., São Paulo: Pearson Prentice Hall.

Meier, K. J.; O’Toole Junior; Laurence, J.; Boyne, G. A.; Walke, R. M. (2007). Strategic Management and the Performance of Public Organizations: Testing Venerable Ideas against Recent Theories. Journal of Public Administration Research and Theory, 17(3), 357-77.

Moura, J. F. P.; Pimenta Filho, E. C.; Gonzaga Neto, S.; Leite, S. V. F.; Guilhermino, M. M.; Menezes, M. P. C. (2010). Análise econômica da exploração de leite no cariri paraibano. Acta Scientiarum Animal Sciences, 32(2), 225-231.

Newman, J. Clarke, J. (1994). Going about our business: the managerialization of public services. In: Clarke, J.; Cochran, A.; McLaughlin, E. Managing Social Policy. London: Sage.

Reinert, C. (2005). Metodologia para apuração de custos nas IFES brasileiras. Dissertação (Mestrado). Universidade Federal de Santa Catarina, Florianópolis, SC.

Silva, M. B.; Grigolo, T. M. (2001). Metodologia da pesquisa e elaboração de dissertação. 3. ed. Florianópolis: EDUFSC.

Silva, M. F.; Silva, A. C. (2013). Análise dos indicadores zootécnicos e econômicos do sistema de produção de leite a pasto com suplementação. Revista Brasileira de Agropecuária Sustentável, 3(1), 110-116.

Slomski, V. (2008). Manual de contabilidade pública: um enfoque na contabilidade municipal, de acordo com a Lei de Responsabilidade Fiscal. 2. ed. São Paulo: Atlas.

Triviños, A. N. S. (1987). Introdução à pesquisa em ciências sociais: a pesquisa qualitativa em educação. São Paulo: Atlas.

Xavier Júnior, A. E.; Queiroz, D. B.; Miranda, K. F. (2013). Demonstração do resultado econômico e eficiência no setor público: Uma avaliação do resultado econômico do curso de ciências contábeis de uma universidade pública federal. In: XX Congresso Brasileiro de Custos, Uberlândia. Anais de congresso. Uberlândia: XX Congresso Brasileiro de Custos. 